\title{
Psicologia e atenção básica: vivências de estagiários na Estratégia de Saúde da Família
}

\author{
Psychology and basic attention: experiences of trainees \\ in Family H ealth Strategy
}

Valdemar Donizeti de Sousa ${ }^{1}$

Vera Engler Cury ${ }^{1}$

\footnotetext{
${ }^{1}$ Programa de Pós-

Graduação em Psicologia, Centro de Ciências da Vida, Pontifícia Universidade Católica de Campinas. Av.John Boyd Dunlop $s / n$, Prédio Administrativo, Jardim I paussurama. 13060-904 Campinas SP. valdsousa2@yahoo.com.br
}

Abstract This study shows a qualitative research based on a humanist theory in relation to the experiences of trainees from the psychology course of PUCCampinas, that are participating in family health teams in the areas of $\mathrm{H}$ ealth/Clinic and basic attention in public health. The partici pants weresix trainees in the last year of the course and located in two $\mathrm{H}$ ealth-School Centers in the N orthwest region of Campinas. The methodology used was an ethnographic view. The processes of data composition were produced in two different moments: a) by weekly register on the trainee's personal diary during five months; b) semi-directed individual interviews at the end of the term. These data were analyzed according to a phenomenological reading. It wasfound evolutive stages in the process of the trainee formation. Initially, the experience was lived with surpriseand strangeness, resulting in contradictory feelings of innapropriation to thei $r$ inexperience to work in teams. On the other hand, because they were well received by the group, there was a personal transformation considered to be very enriching, symbolized as a single felling of belonging, motivating efforts to a creative and integrating clinic practice. Key words Psychological practice in institution, Family health, Humanistic psychology, Psychologists training
Resumo Trata-se de uma pesquisa qualitativa de inspiração teórica humanista acerca das vivências de estagiários do curso de graduação em psicologia da PU C-Campinas na área da Saúde/Clínica, na atenção básica em saúde pública, como participantes de equipes de saúde da família. Participaram seis estagiários do último ano do curso, alocados em dois Centros deSaúde-Escola da região N oroestedeCampinas. A metodologia utilizada foi de cunho etnográfico. 0 processo para composição dos dados foi produzido em dois momentos: a) registro semanal em diário pessoal de cada estagiário, durante cinco meses; b) entrevistas individuais, semidirigidas, ao final do período letivo. Estes dados foram analisadosa partir deuma leitura fenomenológica. Encontraramse fases evoluti vas no processo de formação do estagiário. Inicialmente, a experiência foi vivenciada com surpresa e estranhamento, gerando sentimentos contraditórios de inadequação frente à inexperiência para o trabalho em equipe. No entanto, por terem sido acolhidos e compreendidos pela equipe, ocorreu uma transformação denatureza pessoal eformativa, considerada muito enriquecedora, simbolizada como vivência singular de pertencimento, motivando esforços para prática clínica integradora e criativa. Palavras-chave Práticas psicológicas em instituição, Saúde da família, Psicologia humanista, Formação depsicólogos 
Introdução

A história da profissão do psicólogo confunde-se com a própria inserção deste profissional no campo da atenção à saúde pública e suas vicissitudes. No entanto, ainda prevalece um distanciamento entre a formação depsicólogos na universidadee a realidade da rede pública de saúde. Várias pesquisas de abrangência nacional e estadual, desde me ados da década de setenta ${ }^{1}$ e, mais intensamente, no final da década de oitenta e início dos anos noventa ${ }^{2-5}$, demonstraram o desnível existente entrea formação do psicólogo e a realidade da atuação do profissional de psicologia em exercício na área da saúde pública.

Apesar do distanciamento existente entrea prática da saúde pública e a formação acadêmica, alguns fatos históricos favoreceram a mudança no cenário nacional da saúde pública e, portanto, influenciaram a inserção do psicólogo na rede, o campo da saúde mental e a própria formação do psicólogo. Segundo Dimenstein ${ }^{6}$, há quatro fatores cruciais que influenciaram fortemente a presença do psicólogo no contexto da saúde pública: 1) Todas as circunstâncias que acompanhavam as políticas públicas no final da década de 70 e início da década de 80 , inclusive no que diz respeito à política de recursos humanos para saúde pública; 2) 0 impacto da crise social e econômica no País na década de 80, levando ao encolhimento do mercado privado para todo profissional liberal da saúde; 3) A organização dos "movimentos da categoria" na revisão do papel da psicologia na sociedade da época; 4) A propagação da psicanálise e a "psi cologização da sociedade".

Para Spink ${ }^{7}$, esse campo do saber, que diz respeito à psicologia na saúde pública, "está intimamenterelacionado com as transformações quevêm ocorrendo na inserção do psicólogo na saúde".

A participação desse profissional nas primeiras equipes de saúde mental na década de setenta, a ocupação dos espaços públicos como estratégia do movimento sanitário na década de oitenta, o Programa de Ações Integradas de Saúde (AIS) em 1983, a VIII Conferência N acional deSaúde (CNS) em 1986, a aprovação do Sistema Ú nico de Saúde (SUS) na Constituição Federal em 1988 e, a partir da década noventa, a reorganização da rede básica de saúde a partir da composição das Equipes de Saúde da Família (ESF), têm influenciado fortemente tanto a atuação do psicólogo no cenário da saúde pública como a mudança de alguns princípios básicos da clínica psicológica: 0 enquadre sai do consultório e passa à instituição, exigindo a interação com o meio em que vive o indivíduo. E mais, passa a considerar a rua eo domićlio como settings.
0 contato vai da abordagem individual - a relação entre cliente e terapeuta - à vida, ao trabalho e ao lazer. A impessoalidade dá lugar ao empréstimo de poder contratual à pessoa para sua reabilitação psicossocial ${ }^{8}$.

$E$ as instituições de ensino, responsáveis pela formação profissional dos trabalhadores da área de saúde pública, têm um papel fundamental na implementação do SUS, como responsabilidade social e compromisso público no aperfeiçoamento das condições de saúde e da qualidade de vida das pessoas usuárias dos serviços de saúde. No entanto, não basta promover uma inserção precoce do aluno de psicologia no campo da saúde pública, é essencial que haja docentes qualificados, com formação para prover aos estudantes fundamentação contextualizada tanto em relação ao significado do SUS para a sociedadebrasi leira quanto em relação ao impacto da trajetória da psicologia na saúde pública nas várias esferas: na rede de unidades de saúde pública, nos cargos de gestão econdução do sistema de saúde, nos fóruns decisórios sobre políticas públicas de saúde e nas singulares experiências formativas do estudante de psicologia em saúde pública. De maneira especial, destacam-se as universidades que não têm se omitido em relação a este compromisso.

\section{A formação em serviço de saúde pública em Campinas}

Desde o final da década de setenta einício de oitenta, iniciou-se informalmente a participação e 0 compromisso social da PU C-Campinas na formação de profissionais de saúde na rede básica de saúde do município de Campinas.

Inicialmente, criaram-se quatro postos de saúde comunitários que funcionavam em casas alugadas pela própria universidade: Posto Comunitário de Saúde da Vila Castelo Branco, Posto Comunitário de Saúde do Jardim I paussurama, Posto Comunitário de Saúde do Jardim Campos Elíseos e Posto Comunitário de Saúde do Jardim Novo Campos Elíseos, os quais compunham informalmente a rede primária de atenção à saúde do município, na região $N$ oroeste de saúde de Campinas. A criação desses serviços para a área de atenção primária à saúde visava responder às necessidades locais e às orientações propostas pela Organização Mundial de Saúde (OMS) para uma maior articulação entre universidade e rede pública de saúde. Além dos cursos de M edicina, Enfermagem eCiências Farmacêuticas, progressivamente, outros foram sendo incorporados no novo referencial de 
formação em serviço de atenção básica em saúde pública para prática inter e transdisciplinar de todos os saberes e fazeres: psicologia, nutrição, fisioterapia, terapia ocupacional e fonoaudiologia.

Passado alguns anos dessa parceria entre universidade e Secretaria Municipal de Saúde (SM SCampinas), oficializou-se, em 1996, o convênio global entrePrefeitura M unicipal deCampinase PUCCampinas, para implantação dos Centros de Saúde-Escola (CSE): o Centro de Saúde-Escola Prof. Dr. Pedro deAquino N eto (1993), conhecido popularmente como Centro de Saúde Balão do Laranja, o Centro de Saúde-Escola Integração (1996) e o Centro de Saúde-Escola I paussurama (1998).

No entanto, a experiência pioneira no ensino de psicologia clínica na aten ção básica foi inaugurada em 1986, com a primeira turma de oito estagiários de psicologia do 5o ano. Originou-se da iniciativa de duas docentes responsáveis pelo estágio supervisionado em psicologia clínica em centros de saúde, da Faculdade de Psicologia do Centro de Ciências da Vida (CCV).

A inserção da universidade na atenção básica caminhou para uma maior integração com a Secretaria M unicipal de Saúde, ampliando a entrada dos alunos na rede pública.

No decorrer desses anos, já passaram por esta formação no curso depsicologia, opção saúde pública, mais de trezentos alunos, e a PU C-Campinas acompanha as várias mudanças ocorridas na atenção básica à saúde na rede pública de Campinas: a forte influência do movimento sanitário para composição e formação das primeiras Equipes Mínimas de Saúde M ental na década de setenta, as Equipes para a Atenção Integral à Saúde(AIS) eo processo de municipalização das ações e serviços de saúde na década de oitenta, as equipes para inserção do paciente psiquiátrico e o processo de distritalização para divisão territorial e gestão da rede básica na década de noventa, e a integração das equipes de saúde mental nas equipes de saúde da família, com o Projeto Paidéia deSaúdeda Família em 2001. Essa transformação sócio-histórica pertencea duas grandes reformas tanto no cenário nacional quanto no local: a reforma sanitária e a reforma psiquiátrica; ora uma se destaca, ora se misturam, na construção singular da saúde pública e, portanto, da própria formação em serviço do estagiário de psicologia clínica a partir de uma clínica ampliada para atenção básica à saúde dos munícipes de Campinas.

Vale ressaltar que os estagiários de psicologia foram estimulados a participar das reuniões semanais de equipe desde a organização das primeiras equipes de saúde da família. Portanto, acompanharam de perto os progressos e obstáculos frequentes em qualquer mudança e, em especial, na implantação da estratégia de saúde da família, adotada como modelo para a organização da rede básica.

N este sentido, delineou-se o presente estudo, com o objetivo geral de apreender as vivências de estagiários de psicologia clínica em atividades desenvolvidas como participantes deESF no município de Campinas, significando-as no diálogo cotidiano com o pesquisador.

Atualmente, Campinas conta com 47 centros de saúde, distribuídos em cinco Distritos Regionais de Saúde, sendo que cada centro de saúde tem sob responsabilidade uma determinada área de abrangência. Também, em 2001, a Secretaria Municipal de Saúde de Campinas iniciou a implantação de um projeto e instalação de novas diretrizes para atenção básica à saúde a partir de uma articulação política direcionada para integração e qualificação do Programa de Saúde da Família (PSF), levando em conta o contexto singular da histórica realidade da saúde pública dessa cidade, denominado Projeto Paidéia de Saúde da Família?.

Para Goulart ${ }^{10}$, o modelo implantado em Campinas e alguns outros municípios supera as falhas deixadas pelo programa nacional, destacando-se como um modelo alternativo ao PSF.

A Secretaria M unicipal de Campinas opta por direcionar os recursos do PSF para composição das ESF a partir da rede básica de saúde já existente, implantando a estratégia de saúde da família em todo o município com o intuito de atingir algumas mudanças no modelo de saúde anterior e uma transformação nos paradigmas de atenção e práticas assistenciais à saúde da população.

Esta reestruturação do modelo da atenção à saúde a partir da organização de equipes de referência e equipes de apoio matricial é proposta por Campos $^{11}$ desde 1989. Segundo o autor, o apoio matricial diz respeito a um saber específico e diferenciado deuma determinada especialidadee, quando integrado e compartilhado com os profissionais da equipe de referência, favorece a capacidade de resolução e ampliação da assistência ${ }^{12}$.

Em Campinas, a implantação desse modelo na rede básica de saúde também traz mudanças para a gestão e organização do processo de trabalho dos profissionais de saúde mental, que passaram a ser desafiados a realizar o apoio matricial às equipes de saúde da família enão mais restringirem-se aos atendimentos clínicos dentro deum único centro de saúde. Porém, ainda continuam ofertando assistência especializada de acordo com cada núcleo profissional aos casos que necessitem atendimento e que forem identificados por meio das de mandas das ESF. 
O "apoio matricial" passou a ser a estratégia para a gestão eassistência dos profissionais da saúde mental e apontou novos papéis e funções da equipe, para a integração em relação à ESF, dentre os quais:

- Ofertar apoio e acompanhamento às ESF. No geral, cada profissional de saúde mental (psicólogo, terapeuta ocupacional, psiquiatra e assistente social) matricia uma a duas ESF;

- facilitar a troca de saberes e, ao mesmo tempo, favorecer a formação generalista no próprio serviço a partir de discussões de casos em saúde mental e

- ofertar assistência especializada aos casos demandados a partir da discussão clínica nas ESF ${ }^{13}$.

Toda essa transformação, e a própria inserção das equipes de saúde mental na cidade de Campinas, por meio do apoio matricial às ESF, faz parte de um processo recente, gerador de incertezas, de questionamentos e de frequentes atitudes de resistênciafrenteao novo, ao desconhecido. Esseimpacto inicial tem sido um dos fatores responsáveis pelas indefinições de funções, atribuições e papéis a serem desenvolvidos no modelo alternativo de saúde.

Os Centros de Saúde-Escola do convênio entre Prefeitura Municipal deCampinas e PUC-Campinas estão localizados no Distrito deSaúde N oroeste, com uma população estimada em 165.497 habitantes, correspondendo a $14,72 \%$ da população do município ${ }^{14}$. Apesar de essa região ser caracterizada como uma das mais carentes em equipamentos sociais (escolas, creches, praças e outras áreas de lazer) e apresentar um dos maiores índices defavelização do município, em contrapartida, também demonstra uma expressiva participação comunitária por intermédio da ação de vários movimentos populares (associações de bairros, grupos sociais e religiosos) e organizações nãogovernamentais (ONGs), como uma característica de organização civil, de fortalecimento e deempoderamento das pessoas e da própria comunidade para a conquista de infra-estrutura básica e de serviços públicos essenciais que garantam uma melhor qualidade de vida para todos.

Em relação aos serviços públicos de saúde, 0 Distrito deSaúdeN oroestepossui 27 ESF (ou equipes locais de referência), distribuídas em oito centros de saúde e quatro módulos de saúde da família, para atender um total de 85,62\% da população que depende do SUS (SUS-dependente). A distribuição por centro de saúde (CS) pode ser acompanhada na Tabela 1.

Portanto, essas inúmeras mudanças na área das políticas públicas de saúdee, mais recentemente, a reorganização da assistência à saúde por meio da estratégia de saúde da família trouxeram diversas implicações para a formação do estagiário de psicologia na prática do apoio matricial no contexto das ESF.

\section{Método}

De um ponto de vista da psicologia humanista e, portanto, com profundas raízes epistemológicas na fenomenologia, as respostas para as indagações acerca do cotidiano das pessoas pertencem exclusivamente ao universo da interação com 0 humano, para desvelar como acontece a vivência particular, singular eúnica de cada estagiário.

Para Amatuzzi ${ }^{15}$, "uma das coisas que caracteriza uma psicologia de inspiração fenomenológica éa importância dada ao vivido". Segundo o autor, 0

Tabela 1. Caracterização dos serviços públicos da Região Noroeste de Saúde.

Região Noroeste de Saúde - números da atenção básica

\begin{tabular}{lclccc}
\hline Centro de Saúde & Habitantes & Módulos SF & N.o EQs & N.o Funcl & População SUS-dependente \\
\hline Florence & 33.483 & Rossin & 05 & 98 & $90 \%$ \\
Floresta & 13.654 & C Grande & 03 & 57 & $95 \%$ \\
Integração & 26.295 & - & 03 & 61 & $75 \%$ \\
Ipaussurama & 22.620 & Satélite I & 03 & 53 & $90 \%$ \\
Itajaí & 9.505 & - & 02 & 37 & $85 \%$ \\
Pedro de Aquino & 18.608 & - & 03 & 64 & $80 \%$ \\
Perseu & 11.358 & - & 03 & 57 & $80 \%$ \\
Valença & 29.974 & Lisa & 05 & 92 & $90 \%$ \\
Total & 165.497 & 04 & 27 & 519 & $85,62 \%$
\end{tabular}

Fonte: Sousa ${ }^{32}$. 
vivido torna-seuma manifestação frentea um questionamento, ocorre como uma "reação interior imediata àquilo quenos acontece, antes mesmo que tenhamos refletido ou elaborado conceitos".

N este sentido, compreender a vivência dos estagiários de psicologia na prática do estágio em centro desaúde, a partir deum ponto de vista bem situado no cotidiano de atuação/formação, pode contribuir para a investigação das influências deste tipo de formação em psicologia na constituição do profissional na área da saúde pública.

Participaram desta pesquisa seis estagiários do último ano do curso de graduação em psicologia da PU C-Campinas, pertencentes a dois grupos do estágio supervisionado em psicologia clínica, referentes a dois Centros de Saúde-Escola da região Noroeste de Saúde.

Cada estagiário participou da supervisão grupal por seis horas semanais e permaneceu no centro de saúde mais seis horas, o que compõe um total de doze horas por semana, durante um período deonzemeses, defevereiro a dezembro. M etade do tempo semanal de estágio foi dedicado a atividadesambulatoriais, atuação clínica individual e grupal, e a outra metade, como participante das reuniões semanais das ESF para real ização do apoio matricial (realizado em duplas ou individualmente, em alguns casos). A distribuição dos participantes da pesquisa nos Centros de Saúde-Escola ficou da seguinte maneira: CSE Pedro de Aquino três estagiários e CSE Integração - três estagiários.

\section{Delineamento da pesquisa}

O percurso escolhido para composição dos dados foi produzido nos seguintes momentos: um registro semanal em um diário pessoal de cada estagiário e o depoimento verbal de cada um dos participantes durante uma entrevista semidirigida.

Com a finalidade de descrever a vida cotidiana no contexto do estágio, utilizou-se do recurso denominado versão de sentido (VS) ${ }^{15}$. Trata-se de um registro contínuo e processual, redigido pelo próprio participante, imediatamente após o ocorrido. Segundo o autor da VS, além do uso para a formação de psicoterapeutas, também vem sendo usada em pesquisas qualitativas como um método que possibilita um caminho para "compreensão do sentido do encontro"15. Para um alcance abrangente do processo de formação dos estagiários, o pesquisador elaborou um diário de "Versões de Sentido", que foi entregue a cada estagiário no início do segundo semestre do ano letivo de 2004. Na ocasião, foi explicitada a importância do registro semanal no diário durante todo o período do segundo semestre, como estratégia para se aproximar da vivência imediata do estagiário, para compreensão do processo de formação em serviço ao longo do estágio.

As entrevistas individuais semi dirigidas foram realizadas entre os meses de novembro e dezembro do ano de2004, privilegiando, assim, o final de um período completo de estágio. Seguiu-se o modelo de entrevista do tipo não-diretiva ativa, estruturada a partir de uma pergunta disparadora, buscando intervir o mínimo possível, apenas quando necessário, para estimular uma expressão mais próxima do tema do estudo.

Foram adotados todos os procedimentos éticosque envolvem as pesquisas com seres humanos, conforme Resolução 196/96 do Conselho Nacional de Saúde e segundo termos do Conselho Nacional deÉtica em Pesquisa, CONEP, com respectiva aprovação do Comitê de Ética em Pesquisa da PUCCampinas. Os participantes tiveram total liberdade para se recusar a participar da pesquisa ou para retirar o consentimento, em qualquer fase do estudo, sem nenhum prejuízo para a formação deles.

\section{Análise da mediação dialógica}

Buscou-se apreender as experiências pessoais dos estagiários pela via de uma mediação dialógica, composta deelementos de cunho subjetivo eintersubjetivo:

. Elementos de natureza subjetiva: registros em diário deVersões de Sentido - síntese subjetiva dos estagiários.

. Elementos de natureza relacional/intersubjetivos: entrevistasindividuais semidirigidas com os estagiários - síntese intersubjetiva, construída a partir do encontro do pesquisador com os estagiários.

Os dados foram analisados sob um enfoque qualitativo fenomenológico nas seguintes etapas sucessivas: seleção dos trechos relevantes de cada registro de acordo como o objetivo do estudo (1); agrupamento dos trechos relevantes em um mesmo grupo temático (2); compreensão desse agrupamento, seguida da compreensão psicológica (3) e composição da estrutura geral a partir da comparação dos elementos comuns e divergentes (4).

\section{Resultados ediscussão}

Os resultados obtidos suscitam reflexões enriquecedoras e permitem al gumas constatações de maneira bastante integrada acerca da inter-relação 
entre as várias transformações vividas: a experiência de implantação de uma forma alternativa de modelo de saúde, a inserção no campo da atenção básica, o modo de subjetivar, analisar, agir e viver das pessoas que vivenciam o processo de formação em serviço de saúde pública.

A contextualização da evolução sócio-histórica das várias transformações ocorridas na área da saúdepública no território nacional e, em especial, da história singular da cidade de Campinas até os dias atuais, com a implantação da estratégia de saúde da família, pertence a um processo de continuidade histórica, que diz respeito a uma intensa bagagem acumulada ao longo dos anos por vários atores envolvidos com a saúde pública do país. Diz respeito a um processo histórico e não simplesmente a "uma nova proposta"16. No entanto, para os estagiários deste estudo, trata-se de uma realidadetotalmentedesconhecida, vivenciada com surpresa, em razão de ser a única oportunidade de contato com a realidade da saúde pública oferecida pela faculdade ao longo de toda a graduação. $\mathrm{N}$ os depoimentos, eles demonstraram responsabilizar a universidade e culpabilizá-la pela negligência e omissão em relação à formação do psicólogo para as questões de saúde pública. Esse desconhecimento acerca do campo da saúde pública diante da inserção no estágio também foi evidenciado nos diários de Versões de Sentido, caracterizando a primeira fase do processo de estagiário como uma vivência embaraçosa frente à inexperiência para o trabal ho em equipe de saúde da família. N os documentos do M inistério da Saúde referentes à inter-relação entre a Estratégia Saúde da Família eas instituições de ensino superior, citamsea importância da divulgação e sensibilização das instituições formadoras para esse novo mercado de trabalho em saúde ${ }^{17}$; a projeção de uma reestruturação pedagógica nos cursos de graduação na área da saúde ${ }^{18}$; o papel da educação permanente no envolvimento das ações de transformação nas instituições deensino superior ${ }^{19}$; 0 investimento financeiro, operacional e técnico para as instituições formadoras, interessadas e comprometidas com as diretrizes de educação permanente no $\mathrm{SU} \mathrm{S}^{20}$ e, a partir de 2003, a implementação de uma política de educação para o SUS, como crité rio para integrar as instituições formadoras ao SUS.

Estudo realizado pelo M inistério da Saúde ${ }^{21}$ a respeito da implantação do PSF em dez centros urbanos demonstra que a maioria destes municípios implantou o PSF como um programa paralelo à rede de saúde existente de modo embrionário e em áreas específicas do município. Segundo o estudo, Campinas aparece como uma das poucas cidades que implantaram a estratégia de saúde da família em todo o município de forma acelerada para a organização das unidades básicas de saúde. Ainda nele, apontam-se inúmeros elementos facilitadores e limitantes do desenvolvimento da estratégia de saúde da família em grandes centros urbanos; no entanto, não há nenhuma indicação ou citação referente ao papel das universidades nesse processo. Para os estagiários, a oportunidade de vivenciar uma formação em serviço de atenção básica revela-se como uma mudança da imagem deturpada que possuíam em relação à saúde pública para uma imagem positiva frente à maturidade adquirida ao longo do processo.

Um primeiro aspecto levantado na composição da estrutura geral tanto a partir dos depoimentos quanto dos diários de Versões de Sentido trata da avaliação em relação à vivência do estágio de formação em serviço de atenção básica ao longo do ano. Os estagiários avaliam positivamente a oportunidade do estágio, principalmente em relação à interação, ao convívio, ao vínculo e à integração com os membros da ESF, como condições facilitadoras para a aprendizagem. Este resultado apresenta-se como uma contrapartida em relação aos vários estudos acerca do tema, desde um dos primeiros trabalhos sobre o profissional de psicologia, realizado na cidade de São Paulo ${ }^{1}$, seguido da tese de doutoramento do trabalho do psicólogo em Centros de Saúde ${ }^{22}$ e dos vários estudos do Conselho Federal de Psicologia ${ }^{23-25}$, que demonstram o desnível existente entre a formação do psicólogo e a realidade da prática do profissional de psicologia em saúde pública. Silva ${ }^{2}$ menciona essa desarticulação como um processo derivado do sistema social vigente. Para os estagiários, a formação em um contexto de atenção básica évivenciada como algo que os torna profissionais de fato, e não apenas aprendizes, em razão da autonomia, das responsabilidades e das tarefas de estágio ser idênticas àquelas dos profissionais de saúde.

0 segundo aspecto abordado diz respeito à aprendizagem da prática coletiva einterdisciplinar e da integração da equipe de saúde mental à equipe de saúde da família. De certo modo, o espaço de encontro de diferentes profissionais da saúde, especialmente nas reuniões sistemáticas dos profissionais com os estagiários, constitui um fértil campo pedagógico de saberes e fazeres a respeito do trabal ho em equipe de saúde da família na atenção básica. A leitura dos diários de Versões de Sentido demonstra a evolução do processo de aprendizagem quese inicia com a apropriação das funções e atribuições das atividades realizadas nas reuniões de equipe, passando à compreensão da prática da 
atenção à saúde das famílias, absorvendo essa prática como uma extensão do trabalho da equipe de saúde mental, ampliando para uma atuação coletiva no território e concluindo com a avaliação da atuação dos envolvidos (equipe e estagiários).

Neste sentido, os resultados confirmam que a estratégia de saúde da família favorece a participação eo envolvimento das universidades na capacitação das ESF. Para os estagiários, trata-se de um movimento ininterrupto que compreende tanto a integração entre todos os profissionais, para criação de uma forma alternativa de atenção à saúde, quanto às diretrizes operacionais (reunião de equipe, visita domiciliar, acol himento), para efetivação de uma atenção à saúde que vem sendo denominada de clínica ampliada e diz respeito a um redimensionamento da atenção clínica convencional, individualizada e estritamente centrada no saber deum único especialista.

Em relação à diversidade profissional presente nos membros da equipe, os depoimentos destacam a importância do agente comunitário de saúde, em razão de sua atuação e representação na comunidade e de sua atuação/formação mais abrangente. Vale contextualizar, que no início da década de oitenta, a PU C-Campinas, por meio da implantação dos primeiros postos comunitários de saúde, também criou o cargo de "auxiliar de saúde", contratando pessoas moradoras na região deabrangência do posto comunitário de saúde sem nenhuma formação específica na área.

Um terceiro aspecto refere-se às modificações surgidas com a implantação da estratégia de saúde da família em relação à situação anterior, considerada por Amaral ${ }^{26}$ como uma prática ineficaz para favorecer a integralidade entre a rede básica e as equipes mínimas de saúde mental, em razão da indefinição de uma política de saúde mental, da falta de diretrizes para organização do processo de trabalho das equipes e do baixo envolvimento delas em relação ao cotidiano das unidades básicas e a articulação com as áreas clínicas.

N este aspecto, os resultados evidenciaram a transformação na direção de uma atenção clínica ampliada, como uma atenção de responsabilização resolutiva, integrada no vínculo entre profissional eusuário, engajada na coletividade edemodo interdisciplinar para uma atenção mais qualificada aos usuários. Apesar da constatação de melhorias na organização do processo de trabalho, para um trabalho com maior autonomia e independência, para efetivação de práticas clínicas inovadoras e diferenciadas, também acarretou uma maior exigência de flexibilidade profissional. Para Bezerra ${ }^{27}$, esta clínica ampliada diz respeito a um fazer queleveem conta toda a interação, o conflito e o convívio, ou seja, todo o entorno do usuário e da família, mobilizando os recursos para a busca de resultados no contexto social que eles vivem.

Saraceno, citado por Trad et al..$^{28}$, faz um alerta em relação à transformação de uma abordagem centrada apenas no usuário, para uma atenção voltada para a família, questionando as possíveis generalizações quanto à compreensão do significado da família por parte dos profissionais de saúde, levantando o grave risco de caracterização da família restrita a determinadas organizações familiares, específicas, centradas em um único modelo de vínculo familiar a partir deunião civil e/ou religiosa, com os membros residindo em moradias estáveis e a partir de valores morais segundo os referenciais do profissional de saúde ou da ESF. Esse mesmo autor sugere que o referencial de família deve ultrapassar as fronteiras de uma abordagem linear, apropriando-se das singulares e complexas relações de interdependência presentes na família como "sujeito dinâmico". Devem-se levar em conta todas as pessoas que coabitam, sem considerar se há grau de parentesco entre elas.

Porém, outro fator importante no artigo a respeito do processo do estagiário na formação em serviço foi a trajetória evolutiva da participação do estagiário no cotidiano da reunião de ESF. Para eles, as transformações ocorrem não apenas em termos de mudança no modelo de organização da atenção básica, mas também a partir das influências refletidas na subjetividade de todos os envolvidos no processo de mudança. No caso desse estudo, foi vivenciado um processo inicial deinsegurança e acanhamento para realização do apoio matricial na equipe, conduzindo para um sentimento demaior tranquilidade, atéatingir um nível de satisfação em participar da reunião da equipe, inclusive pelo sentimento de responsabilidade pela condução e organização das reuniões.

Este aspecto sugere outras mudanças nas atribuições da prática do psicólogo e, portanto, na própria formação do estagiário de psicologia, além daqueles citadas por Guarido et al. ${ }^{8}$. M udanças tanto do ponto de vista dos princípios da clínica por intermédio da responsabilidade de acompanhar os casos da saúde mental nas discussões com a equipe como uma espécie de supervisão, para a prática denominada de apoio matricial, como do ponto de vista de gestão na organização e condução das reuniões para o trabalho da ESF.

Para Lancetti ${ }^{29}$, o processo de transformação no modo de gerir e conduzir a rede básica de atenção à saúde, a partir da organização sanitária da estratégia de saúde da família, torna-se a "esteira 
fundamental" de condução e construção de proje tos que facilitem a produção de saúde mental.

Nos depoimentos, os estagiários também re conhecem a visita domiciliar como uma das diretrizes operacionais fundamentais tanto para a transformação da clínica como para a formação em psicologia. Para Cunha ${ }^{30}$, a visita domiciliar é um dos recursos "mais valiosos" do profissional da saúde. Segundo o autor, na realidade do modelo de saúde da cidade de Campinas, a visita domiciliar foi concebida como um "antiprotocolo", pois diz respeito a uma atividade descentralizada da exclusividade do saber especialista e pulveriza-se principalmente como uma tarefa do agende comunitário de saúde, na extensão do serviço de saúde até as moradias.

0 quarto aspecto diz respeito às mudanças de conceitos e paradigmas pessoais em relação à saúde pública, decorrentes da vivência do estágio em centro de saúde. De certo modo, os resultados demonstram que o estágio de psicologia clínica, na atenção básica, adquire uma dimensão altamente instigadora, provocadora e complexificadora, não apenas do ponto de vista do psicólogo na saúde pública, mas também da formação como cidadão, em razão da diversidade de vivências com os vários profissionais, das diferenças entre as famílias dos usuários e das inúmeras situações do cotidiano na interação com a comunidade - questões sociais, culturais e ambientais. Nos depoimentos, os estagiários descrevem a vivência do estágio como al go que ultrapassa o aprendizado acadêmico e diz respeito a uma aprendizagem de forma coletiva entre todas as áreas profissionais da saúde que engloba aspectos cognitivos e afetivos.

Se a formação em serviço acontece através desta diversidade de contextos, espaços e situações, Lancetti ${ }^{31}$ sugere que toda ação em saúde também deve produzir mudanças nas esferas que 0 autor denomina "ecologias inter-relacionadas": condições ambientais, sociais e mentais. A ação integrada em todas elas demonstra, na prática, quea atenção à saúde não separa a pessoa e a população em corpo emente, saúde física esaúde mental, mas diz respeito às questões de saúde de todos - famílias/ usuárias do serviço e profissionais de saúde.

\section{Consideraçõesfinais}

Portanto, a partir dos dados a respeito da vivência do estagiário de psicologia clínica em um serviço de atenção básica ${ }^{32}$, podemos concluir que a formação em serviço é elaborada a partir de quatro modalidades que alicerçam a base para prática do psicólogo: atenção psicológica, atenção coletiva, atenção territorial emodalidade teórico-prática. A modalidade da atenção psicológica traduz as práticas de atendimento aos usuários: psicoterapia individual egrupal, acompanhamento terapêutico (AT), grupos operativos (gestantes, crianças obesas, tabagismo, etc.) e visita domiciliar. A modalidade da atenção coletiva diz respeito ao trabalho junto às equipes de saúde da família e equipe de saúde mental, para 0 acompanhamento, participação nas discussões e matriciamento em psicologia. A modalidade de atenção territorial diz respeito às ações realizadas essencial mente no território, por meio de projetos que envolvam a participação de profissionais de diversas categorias, de diferentes setores e pessoas da comunidade. E a modalidade teórico-prática éo referencial para o embasamento de todas as ações de atenção: supervisão semanal, apoio técnico no campo de estágio do psicólogo de referência da universidade, reconhecimento de toda rede de saúde pública e discussão temática ( políticas desaúde, planejamento em saúde, epidemiologia, clínica ampliada, desinstitucionalização, reabilitação psicossocial, estratégia de saúde da família, trabal ho em equipedesaúde, etc.).

Diante disso, se quiséssemos destacar os pontos mais importantes do estudo, diríamos que:

1. A formação em serviço provoca surpresa e estranhamento em quem esteveal heio a ela durante todo o curso de graduação em psicologia;

2. ela provoca, também, um sentimento deinadequação e desvalia;

3. e, assim, gera uma crise que exige do estagiário uma reviravolta interior, da qual é salvo porque encontra abrigo e atenção num conjunto de profissionais e usuários que constituem uma nova morada para ele;

4. nesse convívio, a mudança pessoal é possível numa direção positiva e enriquecedora; formamse novos vínculos, creditando-se, aos usuários, o direito de lutar por sua autonomia pessoal e, às famílias, o direito à própria identidade;

5. cria-se, então, uma vivência singular de pertencimento - sentir-semembro da equipede saúde;

6. esse sentimento de pertencer leva à autonomia e a novas responsabilidades na condução de tarefas, já na condição de psicólogo e

7. o fazer integrado ocupa o cotidiano e redimensiona os saberes; uma clínica compartilhada e resolutiva vai surgindo para o estagiário, e ele a compreendevivendo.

Independente do referencial teórico a ser adotado, da abordagem a ser seguida, o tripémetodológico utilizado, integrando a atitude etnográfica aliada ao uso dos registros de versão de sentido e dos de- 
poimentos para compreensão por meio de uma leitura fenomenológica, demonstra a importância de se compreender o significado que a formação em serviço tem para o próprio aprendiz. E, a partir dessa compreensão, pensar nas particularidades da proposta pedagógica demonstra quea existência do tipo de formação em serviço de atenção básica não necessariamenteimplica o descrédito em relação a outras formas de formação em psicologia clínica. No entanto, aponta a necessidade urgente de problematização da formação acadêmica e sugere a com-

\section{Colaboradores}

VD Sousa e VE Cury participaram igualmente de todas as etapas da elaboração do artigo. plementação com outros estudos, que ouvissem outros atores e envolvidos nesse mesmo universo de formação dos estagiários, ou seja, os funcionários, membros das ESF (agentes comunitários de saúde, médicos generalistas, enfermeiros, auxiliares deenfermagem, pediatras, ginecologistas, psicólogos, terapeutas ocupacionais, psiquiatras, além dos docentes-supervisores e usuários do sistema de saúde), para assim, enriquecer ainda mais a complexidade das várias intersubjetividades presentes no cotidiano deformação em serviço deatenção básica.

\section{Referências}

1. M elo SL. Psicologia e profissão em São Paulo. São PauIo: Ática; 1975.

2. Silva RC. A formação em psicologia para o trabalho na saúde pública. In: Braga Campos FC, organizadora. Psicologia e saúde: repensando práticas. São Paulo: Hucitec; 1992. p. 25-40.

3. Yamamoto $\mathrm{OH}$. A crise e as alternativas da psicologia. São Paulo: Edicon; 1987.

4. Yamamoto $\mathrm{OH}$. Apontamentos para um estudo da psicologia em $N$ atal: áreas de atuação e seus determinantes. Rev Psicol 1988; 1:3-13.

5. Jackson AL, Cavallari CD. Estudo sobre a inserção do psicólogo nas unidades básicas de saúde. Cad CRP 6a Região 1991; 7-31.

6. Dimenstein MDB. 0 psicólogo nas unidades básicas de saúde: desafios para formação e atuação profissionais. Estud Psicol (Natal) 1998; 3(Supl. 1):53-81.

7. Spink MJ. A formação em psicologia para o trabalho na saúde pública. In: Braga Campos FC, organizadora. Psicologia e saúde: repensando práticas. São Paulo: Hucitec; 1992.

8. Guarido EL, Braga Campos FC. Clínica ampliada é prática do psicólogo na saúde Pública. Múltipla Revista de Psicologia CRP SP 2001; 1:38-41.

9. Prefeitura Municipal de Campinas. Projeto Paidéia Saúde da Família, programa da Secretaria M unicipal de Saúde. Campinas: Secretaria M unicipal de Saúde; 2001.

10. Goulart FAA. Experiências em saúde da família: cada caso é um caso? [tese]. Rio de Janeiro (RJ): Escola Nacional de Saúde Pública, Fundação Oswaldo Cruz; 2002.

11. Campos GWS. Equipes de referência e apoio especializado matricial: um ensaio sobre a reorganização do trabalho do trabalho em saúde. Cien Saude Colet 1999; 4(2):393-403.

12. Campos GWS. Apoio matricial e equipe de referência: uma metodologia para gestão do trabalho interdisciplinar em saúde. Cad Saude Publica 2007; 23(2):399407.

13. Prefeitura M unicipal de Campinas. Saúde mental: apoio matricial ao paidéia - Saúde da Família. Campinas: Secretaria M unicipal de Saúde; 2001. 
14. Prefeitura Municipal de Campinas. Relatório de Gestão 2001-2004 do Distrito de Saúde N oroeste. Campinas: Secretaria M unicipal de Saúde; 2004.

15. Amatuzzi MM. Por uma psicologia humana. Campinas: Alíena; 2001.

16. Souza HM . O futuro tecido no presente. Rev Bras Saúde da Família 1999; 1(1):7-9.

17. Brasil. M inistério da Saúde. Saúde da família: uma estratégia de organização dos serviços de saúde. Brasília: Ministério da Saúde; 1996.

18. Brasil. M inistério da Saúde. Saúde da família no Brasil: linhas estratégicas para o quadriênio 1999/2002. Brasília: M inistério da Saúde; 1999.

19. Brasil. Ministério da Saúde. Caminhos para a mudança da formação e desenvolvimento dos profissionais de saúde: diretrizes para a ação política para assegurar educação permanente no SUS. Brasília: M inistério da Saúde; 2003

20. Brasil. Ministério da Saúde. Política de educação e desenvolvimento para o SUS: caminhos para a educação permanente em saúde - pólos de educação permanente. Brasília: M inistério da Saúde; 2003.

21. Brasil. Ministério da Saúde. Saúde da família: avaliação da implementação em dez grandes centros urbanos: síntese dos principais resultados. Brasília: Ministério da Saúde; 2005.

22. Silva RC. 0 trabalho do psicólogo em centros de saúde: algumas reflexões sobre as funções da psicologia na atenção primária à saúde [tese]. São Paulo (SP): Instituto de Psicologia, Universidade de São Paulo; 1988.

23. Conselho Federal de Psicologia. Quem é o psicólogo brasileiro? São Paulo: Edicom; 1988.

24. Conselho Federal de Psicologia. Psicólogo brasileiro: construção de novos espaços. Campinas: Átomo; 1992.
25. Conselho Federal de Psicologia. Psicólogo brasileiro: práticas emergentes e desafios para a formação. São Paulo: Casa do Psicólogo; 1994.

26. Amaral MA. Atenção à saúde mental na rede básica: estudo sobre a eficácia do modelo assistencial. Rev. Saude Publica 1997; 31(3):288-295.

27. Bezerra B. A clínica e reabilitação psicossocial. In: Pitta AM F, organizadora. Reabilitação psicossocial no Brasil. São Paulo: Hucitec; 1996. p. 137-42.

28. Trad LAB, Bastos ACS. 0 impacto sócio-cultural do Programa de Saúde da Família (PSF): uma proposta de avaliação. Cad Saude Publica 1998; 14 (Supl. 2):429435.

29. Lancetti A. Saúde Mental nas entranhas da metrópole. In: Lancetti A, organizador. Saúde e loucura 7: saúde mental e saúde da família. São Paulo: Hucitec; 2000. p.11-52.

30. Cunha GT. A construção da clínica ampliada na atenção básica. São Paulo: Hucitec; 2005.

31. Lancetti A. Síntese metodológica. In: Lancetti A, organizador. Saúde e loucura 7: saúde mental e saúde da família. São Paulo: Hucitec; 2000. p.117-120.

32. Sousa VDS. 0 psicólogo e a saúde pública: uma leitura fenomenológica das vivências cotidianas de estagiários na atenção básica [tese]. Campinas (SP): Faculdade de Psicologia, Pontifícia Universidade Católica de Campinas; 2006.

Artigo apresentado em 06/01/2007

Aprovado em 08/10/2007

Versão final apresentada em 26/11/2007 